\title{
La publicidad integrada en el contenido TV: Atención visual y reconocimiento cognitivo en los jóvenes y en los adultos mayores
}

\author{
Elena AÑÑNOS ${ }^{1}$ \\ Anna VALLI ${ }^{2}$ \\ Universidad Autónoma de Barcelona
}

\begin{abstract}
RESUMEN:
El objetivo principal de este trabajo es llenar un vacío existente en la investigación sobre la eficacia de la publicidad integrada en los contenidos televisivos, estudiando y midiendo de forma objetiva (Eye Tracker) cómo los espectadores atienden y procesan este tipo de comunicación publicitaria. Los datos muestran en qué medida la atención visual dispensada a los elementos de la publicidad integrada está relacionada con el posterior reconocimiento de la publicidad y de la marca, y si este proceso difiere entre los sujetos jóvenes y los adultos mayores. Los resultados permiten concluir que el proceso atencional a la publicidad integrada se produce en diferentes niveles, de los cuales se constata el primer nivel, el pre-consciente, pre-atentivo e involuntario, en el que las fijaciones oculares del sujeto exploran los elementos publicitarios de forma inconsciente; en función de otros mecanismos de selección, los elementos publicitarios se procesarán en un nivel superior hasta el punto de ser reconocidos por el telespectador. Consideramos la televisión, y en especial la inclusión simbiótica de publicidad integrada, como una herramienta de comunicación muy eficaz para las marcas. Esta herramienta, la publicidad integrada o por extensión, el Content Integrated Marketing, puede satisfacer de forma amplia y efectiva las necesidades de comunicación de la marca. Esta aportación al estudio de la publicidad desde la perspectiva de la psicología cognitiva aborda cuestiones novedosas sobre la publicidad integrada, dando respuesta a algunas preguntas y planteando otras nuevas, y abre la puerta a posteriores investigaciones sobre la publicidad desde una perspectiva interdisciplinar.
\end{abstract}

PALABRAS CLAVE: Publicidad Integrada; Televisión; Atención Visual; Eye Tracker; Reconocimiento Cognitivo; Percepción Inconsciente

TITLE: Integrated Advertising in TV content: visual attention and cognitive recognition in young and in older adults

\begin{abstract}
:
The aim of this study is to address the lack of research on effectiveness of Advertising in TV content, studying and measuring objectively (Eye Tracker) how the audience pays attention and processes this Integrated Advertising. The data shows in what extent the visual attention delivered to Integrated Advertising elements is related to the subsequent recognition of the Advertising and the Brand, and if this process differs among subjects, younger and older adults. The results suggest that attention processing of Integrated Advertising occurs at different levels, the first level being the pre-conscious, pre-attentive and involuntary, the level in which the eye fixations of the subjects are delivered in Advertising elements unconsciously; according to various selection mechanisms, advertising items

1 Doctora en Psicología por la Universidad Autónoma de Barcelona (UAB). Profesora Titular de Universidad en las facultades de Ciencias de la Comunicación y de Psicología, especializada en la docencia de Psicología de la Comunicación Publicitaria y de la Psicología de la Percepción aplicada a la Publicidad y a la Comunicación Audiovisual. Email: elena.ananos@uab.cat

2 Licenciada en Publicidad y Relaciones Públicas (UAB). Profesional de la Publicidad especializada en Digital Media. Email: annavallicasado@gmail.com
\end{abstract}


are processed at a higher level until being recognized by the viewer. Consequently we do believe TV, and precisely the inclusion of symbiotic Integrated Advertising, is indeed a very effective communication tool for brands. This tool, Integrated Content Marketing, can fulfil effectively a vast range of Brand Communication needs. This contribution to the study of Advertising from the perspective of Cognitive Psychology deals with new issues on Integrated Advertising, answering questions and setting out new ones, and opens the door to further research on Advertising from an interdisciplinary perspective.

KEY WORDS: Integrated Advertising; TV; Visual Attention; Eye Tracker; Cognitive Recognition; Unconscious Perception

\section{Introducción y marco teórico}

\subsection{Publicidad integrada en el contenido televisivo}

Los últimos años han estado plagados de cambios en los medios de comunicación (el apagón analógico), tanto en su comercialización, a partir del cese de bloques publicitarios en TVE, como en su consumo, a partir del auge de los medios interactivos y de la conectividad a internet desde las diferentes pantallas. Como consecuencia, también ha cambiado la Publicidad que en ellos se inserta.

De hecho, más que de medios, podemos hablar de diferentes canales de distribución de contenidos que ya no son independientes sino que aparecen permanentemente relacionados entre sí, nutriéndose unos de otros, en constante interacción, y que incluyen también contenidos creados por las marcas con un objetivo de comunicación específico. Su apariencia y sus formatos publicitarios han cambiado. Por supuesto que el irreductible spot de 30 segundos sigue existiendo en televisión, si bien su distribución a través de las redes sociales está ganando importancia y adquiriendo una nueva entidad y uso. El IAB (Interactive Advertising Bureau) sigue contemplando y sistematizando la clasificación de los formatos interactivos (skyscrappers o rascacielos, layers, roba páginas, etc.), pero en el panorama actual encontramos más formatos o formas de Publicidad, menos evidente y menos estandarizada y, a priori, más eficaz: la Publicidad Integrada.

A modo de acotación del término, entendemos como Publicidad Integrada el placement o ubicación del producto anunciado, de la marca, o de los contenidos creados por una marca, en el programa o contenido televisivo. A nivel general, el producto aparece interactuando con los contenidos y/o es mostrado por los actores o presentadores; la marca o su logotipo aparecen en forma de banner o animación o bien es mencionada o recomendada -endorsement-por parte de los actores o los presentadores del programa; los contenidos creados por una marca pueden contener el producto o la marca de forma explícita o no, son de interés para su público y su objetivo es crear engagement con la marca.

La publicidad Integrada se funde, pues, con el contenido presente en la pantalla, se inserta de modo simbiótico (o debiera ser así para que fuera eficaz) en la continuidad de los contenidos audiovisuales, evitando la disruption (DRU, 1997), interactuando a menudo con presentadores o actores (product placement), y creando la duda de si pasa 
o no inadvertida para el consumidor de contenidos. ¿Es realmente así? y si así fuera, ¿sería efectiva? Para los anunciantes, este nuevo panorama televisivo se traduce en la exigencia de crear formatos publicitarios que se integren en los distintos contextos de visionado del telespectador y que logren captar su atención. En este sentido, la competición en el mercado está en constante crecimiento, a la vez que crecen las necesidades y los requerimientos de los consumidores; por tanto, si las marcas quieren obtener una ventaja competitiva, deberán obtener un conocimiento detallado no sólo de las necesidades del target, de sus opiniones y de sus motivaciones, si no también de cómo procesa, cognitivamente, la información publicitaria. Ello sólo se puede adquirir introduciendo en la investigación marquetiniana las aportaciones y los nuevos descubrimientos obtenidos de diferentes ramas de la ciencia, como la ciencia psicológica, especialmente en su estudio de los procesos cognitivos, la sociología y la neurociencia (neuromárqueting). Los datos obtenidos únicamente a partir de las medidas verbales no son suficientes y para conocer el procesamiento de la información publicitaria se hace necesario registrar de forma objetiva sus indicadores cognitivos.

Este trabajo se enmarca en el estudio de los mecanismos cognitivos atencionales y del procesamiento de la información de la publicidad integrada en el contenido televisivo. En concreto, estudia cómo operan la atención visual y el reconocimiento cognitivo cuando aparece la publicidad integrada en la pantalla televisiva, utilizando como fuente de medida el Eye Tracker.

\subsection{Atención visual a la publicidad integrada y su medida}

El objetivo de la publicidad, y también de la publicidad integrada es conseguir la atención del telespectador. Es importante, pues, conocer cuáles son los mecanismos de la atención visual que operan en este proceso en el que mientras el telespectador está visionando unos contenidos televisivos que normalmente corresponden a la programación, aparece en la pantalla la que consideramos publicidad integrada en el contenido, es decir, una serie de formatos publicitarios que no interrumpen el visionado del programa, a los cuales el sujeto no tiene, en principio, intención de atender y que a menudo se ven reforzados en el diálogo de los personajes (¿irrelevantes?). ¿Cuál es el mecanismo atencional que opera en este proceso? Hablar de atención y publicidad nos lleva a hablar del concepto de visualidad, definida como la capacidad que tiene la composición gráfica y los elementos que la integran de atraer la atención del sujeto (AÑAÑOS y otros, 2009). Pero la atención no es un concepto fácil de medir. Desde la psicología existen diferentes perspectivas teóricas que se pueden aplicar en el estudio de los elementos atencionales relacionados con este tipo de publicidad, partiendo de la base que el mecanismo que opera es la atención visual, definida por HENDERSON (1992) como el uso selectivo de información de una región del campo de visión a costa de no seleccionar otras regiones del mismo campo visual. En el caso de la TV, la mirada del espectador selecciona del campo visual, determinado por la pantalla, aquellos contenidos de la programación que le son relevantes; se trata de comprobar si los elementos de la 
publicidad integrada que aparecen inmersos en los contenidos son capaces de captar la atención del telespectador, y de ser así, conocer cómo se produce la captura atencional. Desde el punto de vista cognitivo, el estudio de la captación atencional en esta compleja situación, se puede realizar desde diferentes perspectivas teóricas que explican cómo estímulos que en principio son irrelevantes para el sujeto logran captar su atención.

Uno de los referentes teóricos sobre el funcionamiento del estudio de la atención selectiva parte del estudio de LACHTER, FORSTER y RUTHURK (2004); estos autores, siguiendo la teoría del filtro selectivo de Broadbent, consideran que la atención funciona como un filtro y que puede ser dirigida de una fuente de estimulación a otra. Este filtro se encuentra en la entrada de la información y está sujeto a serias limitaciones de capacidad; en él se realiza un análisis pre-atencional de las características físicas del estímulo y se determina qué estímulos pasarán a un nivel de procesamiento superior. Siguiendo este planteamiento, las características físicas de los elementos de la publicidad integrada se captarán en un nivel pre-atencional y en función de otros mecanismos de selección, serán procesadas en un nivel superior.

Desde el modelo de redes atencionales (POSNER y PERTERSEN, 1990), una de las funciones más estudiadas de la red atencional posterior es la orientación de la atención hacia un lugar del espacio donde aparece un estímulo potencialmente relevante porque posee propiedades únicas, es novedoso o aparece de forma repentina en la escena visual; estos estímulos novedosos, no esperados, tienen la capacidad de capturar nuestra atención de forma automática (orientación atencional exógena involuntaria); siguiendo este modelo, la publicidad integrada, y especialmente aquella que aparece de repente en un lugar de la pantalla, constituirá el estímulo relevante que captará la atención del telespectador. Recientemente, desde el estudio de la atención visual se investiga el fenómeno de la captura atencional, es decir las condiciones en las cuales estímulos irrelevantes obtienen prioridad atencional involuntaria. La captura atencional se produce de forma automática (a partir de factores exógenos) pero también puede ser susceptible de modulación endógena (RUZ y LUPIÁÑEZ, 2002; BOTTA y LUPIÁÑEZ, 2010; PACHECO, LUPIÁÑEZ y ACOSTA, 2009). En este sentido, es evidente que la publicidad utiliza estímulos exógenos, que corresponden básicamente a las características del anuncio, para capturar de forma involuntaria la atención del sujeto.

¿Estímulos relevantes o estímulos distractores? Según lo descrito en los párrafos anteriores, la publicidad integrada se puede considerar como un estímulo nuevo, que aparece en la pantalla y que capta, en función de sus características, la atención del telespectador mediante el fenómeno de la captura atencional. Desde la perspectiva teórica del Efecto de Compatibilidad de Flancos (ECF), este tipo de publicidad aparecerá como un estímulo distractor. El ECF muestra como la identificación de un estímulo objetivo se puede ver modificada por otros estímulos llamados Flancos o distractores que son procesados (de forma automática) incluso cuando se instruye al sujeto para que los ignore (PEDraja, MonToro y García SEVILla, 2010). Si aplicamos la teoría del ECF a los posibles efectos de la publicidad integrada, podemos considerar que estos formatos aparecen en la pantalla como un nuevo elemento (distractor) al que el teles- 
pectador no tiene, en principio, intención de atender, si bien serán procesados de forma automática, similar a como se procesan los flancos, y tendrán un claro efecto sobre la atención (PIETERS y WEDEL, 2007). El procesamiento semántico de los distractores mientras la atención está puesta en otra parte corresponde al "Leakage" o escape (LACHTER, FORSTER y RUTHRUFF, 2004); en el escenario de la publicidad integrada en los contenidos televisivos, es evidente que estos formatos invaden la pantalla intentando conseguir (a modo de escape) la atención del telespectador.

¿Podemos hablar de diferentes niveles de atención a los estímulos publicitarios? HEATH, NAIRN y BOTTOMLEY (2009) estudian los efectos de la atención en los elementos o estímulos publicitarios y consideran que durante el proceso de selección, el sujeto tiene que decidir a qué estímulos dedica la atención y cuánta atención dedica, si bien no siempre controla de forma activa (¿consciente?) este proceso. HEATH (2009) define estos niveles de atención como la suma de los recursos cognitivos que se dispensan en cada momento. SMIT, NeIJENS y HEATH (submitted) definen la atención como el proceso de selección de la información en el cual diferencian 4 niveles, fases o procesos: el proceso subconsciente, la fase de la atención pasiva, la fase de la atención activa y el proceso de elaboración. Durante el proceso inconsciente, el sujeto explora el anuncio y su alrededor de forma inconsciente, filtrando la información entrante; en este nivel se pueden procesar de forma inconsciente procesos emocionales y elementos heurísticos. En la fase de la atención pasiva se dispensa la atención suficiente para poder decidir si merece la pena atender el anuncio. En la fase de atención activa el sujeto empieza a dispensar atención consciente al anuncio, lo cual implica que éste podrá dejar huellas en la memoria. Finalmente, en el proceso de la elaboración, el sujeto utiliza las plenas capacidades atencionales que le posibilitan la comprensión y la reacción cognitiva. Estos cuatro niveles siguen un orden jerárquico y requieren un incremento progresivo de las capacidades cognitivas; no obstante, en función del objetivo del sujeto, se puede dar un proceso divergente en el cual se pase de la atención pasiva al proceso de elaboración de la información. Siguiendo este planteamiento, la publicidad integrada se procesaría en el primer nivel (subconsciente); conocer cómo la información procesada pasa, y en qué medida lo hace, a la fase de la elaboración (consciente) es uno de los retos actuales de la investigación publicitaria.

Aceptamos, a partir de lo descrito hasta ahora, que al menos desde el punto de vista teórico, la publicidad sobreimpresionada se procesa a un nivel pre-atentivo e involuntario, inconsciente y automático. Pero ¿qué efectos produce en el telespectador? Según GRIMES (2006), la publicidad televisiva es capaz de crear efectos con niveles bajos de atención baja o low attention; este autor propone un modelo según el cual, en condiciones de low attention, la publicidad puede crear efectos en dos vías paralelas, la perceptiva y la conceptual, si bien es prácticamente inexistente la investigación en este sentido.

¿Cómo se puede medir la atención visual? El Eye Tracker se ha consolidado como una metodología muy válida para identificar la atención y los elementos que la atraen; es una metodología directa y no intrusiva para registrar las características de las fija- 
ciones y de los movimientos oculares, los cuales son verdaderos indicadores de la atención visual (WEDEL y PIETRES, 2007). El Eye Tracker tiene varias aplicaciones en investigación, especialmente en la psicología cognitiva pues aporta una información muy relevante sobre la atención visual y la identificación y categorización visual de objetos visuales, tal y como lo demuestran numerosos estudios entre los que destacan los de ABBOT (2006) y ALTMANN y KAMIDE (2009). En publicidad, el Eye Tracker se ha convertido en la base del uso de las aplicaciones comerciales que incluyen el uso de la web, la distribución del packaging y el diseño de productos, entre otros. Los registros y el estudio de las características de las miradas, de las fijaciones oculares, los mapas de calor y las trayectorias visuales, aportan una valiosa información sobre la atención visual: el Eye Tracker nos informa si hay atención visual y en qué medida. Abundantes estudios abalan la validez de la información del ET para medir la atención que prestan los consumidores a los anuncios y también para medir la atención subconsciente a las marcas (BRASEL y GIPS, 2008).

\subsection{Reconocimiento cognitivo de la publicidad integrada}

Aceptamos que la publicidad integrada será atendida a nivel preconsciente, inconsciente o de forma pasiva. Pero, ¿en qué medida será procesada? La atención visual describe dónde los ojos fijan la mirada, pero no es capaz de informarnos si la información ha sido procesada, elaborada o reconocida conscientemente.

La investigación realizada desde la psicología argumenta que la respuesta cognitiva depende directamente del grado de atención focalizada en el estímulo. La atención es, pues, el mecanismo clave inmerso en el reconocimiento de los estímulos, y también (por defecto), de los estímulos publicitarios, si bien el proceso no se da de forma aislada, ya que el reconocimiento de los estímulos publicitarios requiere un proceso complejo en el que intervienen otros procesos cognitivos. Su relación no es fácil de establecer, debido a su complejidad y también al hecho que la mayor parte de la evidencia empírica existente estudia los diferentes mecanismos y procesos cognitivos de forma independiente. Además, existen diferentes formas de definir el reconocimiento cognitivo y el reconocimiento de la publicidad y el mismo concepto se ve a menudo enmascarado de conceptos como identificación, recuerdo consciente, memoria, etc. Estudios recientes plantean la relación entre la atención, la memoria y el reconocimiento de estímulos publicitarios, así como también la influencia de los elementos persuasivos de la comunicación publicitaria. La revisión de estudios realizada por BIEL (2009) muestra que los avances en neuropsicología apuntan a la necesidad de diferenciar entre reconocimiento y memoria, en el sentido que el reconocimiento de estímulos es una tarea más emocional mientras que el recuerdo es una tarea más lógica. BIEL $(2005,2009)$ plantea que el proceso de reconocimiento se lleva a cabo en el hemisferio derecho del cerebro, es decir, en el que está más relacionado con los patrones emocionales, mientras que la memoria, propiamente dicha, se procesa en el hemisferio izquierdo, es decir, 
aquél que requiere una máxima actividad cuando la tarea requerida implica el pensamiento lógico.

En este estudio planteamos el reconocimiento cognitivo del estímulo publicitario en los términos que se derivan de los diferentes niveles de atención propuestos por HEATH (2009), descritos en el apartado anterior; el reconocimiento correspondería al último nivel, en el que se reconoce el estímulo publicitario, es decir se procesa de forma consciente a través de la identificación.

La publicidad integrada se atiende en función de factores que dependen tanto de sus características, como de las características del telespectador y del entorno en el que aparece). Pero, ¿es realmente eficaz? ¿qué procesa y/o reconoce realmente el sujeto? En un estudio realizado en el que se compara el procesamiento consciente e inconsciente del programa y de los elementos de la publicidad integrada (AÑAÑOS y VALLI, 2011) se observa cómo estímulos publicitarios a priori irrelevantes para el consumidor de contenidos, captan su atención, y como el hecho de correlacionar diversos elementos (packaging interactuando con personajes, locución del presentador e imagen animada del producto) con la Marca anunciada, genera en el telespectador un procesamiento global que facilita el recuerdo y refuerza la comunicación publicitaria a la vez que la integra con el contenido del programa. Estudios sobre eficacia y procesamiento cognitivo (VAN REIJMERSDAL, 2009) evidencian como diferentes formatos de publicidad no convencional afectan positivamente a la preferencia de la marca anunciada. ¿Qué ocurre cognitivamente cuando se presentan simultáneamente (Branded Content) diferentes elementos como el producto, la marca, el programa y además se hace mención oral de alguno de ellos? El cerebro humano es lo suficiente complejo para poder tener una respuesta unidireccional. Según el Emotional Engagement Model (HEATH, 2009), la televisión requiere un nivel bajo de atención , y sin embargo, tiene un gran nivel de engagement, lo cual favorece la construcción de la fuerza de las marcas.

En definitiva, los procesos cognitivos inmersos en el hecho de mirar la televisión y procesar su información (publicitaria, en este caso) son complejos y las teorías que los pueden sostener, tienen, hoy por hoy, más datos derivados de los laboratorios experimentales que de estudios realizados con ejemplos reales de programación o de publicidad integrada en la programación.

El siguiente planteamiento, que surge sobre los efectos atencionales de la publicidad integrada, es conocer si afecta evolutivamente a todos los sujetos por igual. Desde la psicología se estudia la evolución de las diferentes aptitudes cognitivas debidas al envejecimiento. Así, el mecanismo de la atención sufre cambios con la edad que se manifiestan en un declive en la tasa de exactitud en la detección de señales, que podría interpretarse como una disminución progresiva del grado de vigilancia que se manifiesta en tareas que requieren atención sostenida. Es decir, en los adultos mayores la atención, sobre todo si debe ser mantenida voluntariamente, disminuye. Por otra parte, el déficit en la atención selectiva se ha explicado a partir de la dificultad mostrada en la discriminación entre estímulos relevantes e irrelevantes, lo que significa que se trata más de un problema perceptivo. Es importante señalar que las alteraciones que puedan 
presentarse en la atención del adulto mayor están íntimamente relacionadas con la motivación que despierte la tarea que se esté acometiendo, y con las alteraciones perceptivas que pudieran estar relacionadas con la edad, de forma que, en condiciones ambientales desfavorables, la atención mantenida podría debilitarse, mientras que en ambientes estimulantes y tareas de interés, podría lograrse una optimización de la atención del senescente (SÁNCHEZ GIL y PÉREZ MARTíNEZ, 2008).

En relación a la atención visual, existe una división de teorías; algunas demuestran que la latencia en las fijaciones visuales y el seguimiento visual fluido se incrementa con la edad, si bien no existe evidencia de la disminución de la precisión de los movimientos oculares. Algunos estudios revelan que la precisión de las fijaciones minvan con la edad, mientras que otros no encuentran ningún efecto relacionado con el envejecimiento y, si bien los jóvenes muestran una mejor precisión en el seguimiento fluido de los movimientos oculares en relación a la gente mayor, la diferencia es muy pequeña. No se han encontrado claras evidencias de que la precisión de los movimientos oculares cambie de forma significativa con la edad; es posible que las diferencias de edad observadas sean más causadas por las diferencias en la percepción del movimiento que por las diferencias en los movimientos oculares, tal y como ya apuntaban SHARPE y SYLVESTER (1978). En relación a la memoria, los estudios muestran cómo con el avance de la edad, la memoria primaria, entendida como almacén transitorio de la información, de capacidad limitada y centro de la atención consciente, prácticamente no sufre deterioro excepto en la rapidez de la recogida de información. Por el contrario, la capacidad de procesamiento y retención de la memoria secundaria, que constituye el almacén permanente de información procedente de la memoria primaria (DURANTE y PEDRO, 2004) puede verse seriamente afectada con el envejecimiento (CHARCHATFIOCHMAN y colaboradores, 2005).

Estos resultados nos llevan al planteamiento de que en función de la medida utilizada en la atención visual y en el reconocimiento, los resultados de los sujetos mayores estarán más influenciados por el deterioro cognitivo, si bien la ausencia de estudios publicitarios de este nivel realizados con este target nos sumerge en una ausencia de referentes que nos permitan hipotetizar sus resultados, más allá de pensar que la publicidad integrada tiene efectos, también en los adultos mayores, sobre la atención y la memoria, y por lo tanto en su procesamiento pre-atentivo y en su posterior reconocimiento.

\section{Objetivos e hipótesis}

El objetivo principal de este estudio es llenar un vacío existente en la investigación sobre la eficacia cognitiva de la publicidad integrada en los contenido televisivos, estudiando y midiendo de forma objetiva (Eye tracker) en qué medida los espectadores atienden y procesan este tipo de comunicación publicitaria. Interesa conocer también en qué medida la atención visual a los elementos de la publicidad integrada está 
relacionada con el posterior reconocimiento de la publicidad y de la marca anunciada, y si este proceso difiere entre los sujetos jóvenes y los adultos mayores.

Las hipótesis generales planteadas son:

- Hipótesis 1. La atención visual dispensada en la pantalla televisiva durante la aparición de publicidad integrada se concentra en diferentes zonas, que se corresponden con las zonas que contienen los elementos publicitarios integrados en el contenido del programa.

- Hipótesis 2. La atención visual en la pantalla durante la emisión de publicidad integrada difiere en las diferentes zonas de la pantalla (las que contienen la publicidad integrada y las que no) y en los diferentes grupos de edad.

- Hipótesis 3. La publicidad integrada favorece el reconocimiento de los elementos publicitarios y de la marca si bien difiere entre los diferentes grupos de edad.

- Hipótesis 4. La atención visual dispensada a los elementos de la publicidad integrada influye en el reconocimiento de la publicidad y de la marca.

\section{Metodología}

\subsection{Material}

Para la realización de la investigación se utiliza el siguiente material:

Fragmento (clip) de $T V$ del programa El Hormiguero (LA CUATRO) que contiene publicidad integrada (Integrated Advertising -IA-). La duración del estímulo (clip) es de 35 segundos, de los cuales 10 incluyen la IA: durante estos 10 segundos aparecen en la pantalla el diálogo entre el presentador y los invitados, la presentación verbal por parte del presentador del Packaging o producto anunciado (el presentador lo nombra y lo muestra) y un banner animado (en la parte inferior) que, sin romper la continuidad del programa, muestra el producto anunciado (en los extremos) y la marca anunciante (en la parte central).

Eye Tracker (ET). Permite estudiar las fijaciones y los recorridos oculares del sujeto mientras visualiza el estímulo (fragmento de TV). Se utiliza el modelo TOBII T60, basado en la emisión y recepción de infrarrojos que dispone de un sistema no intrusivo para el sujeto. Consta de una sola pantalla de 17" TFT que integra la tecnología del ET y opera automáticamente. El sujeto sólo debe situarse delante de la pantalla, esperar a que se realice la calibración de la mirada y visionar las imágenes (estímulos) que se le presentan.

Grabadora digital. Se utiliza para registrar oralmente la respuesta del sujeto correspondiente al reconocimiento del contenido visionado. 


\subsection{Sujetos participantes}

Participan en el estudio 43 sujetos (27 jóvenes y 16 adultos mayores). Los jóvenes (20 mujeres y 7 hombres) son estudiantes universitarios con edades comprendidas entre los 18 y los 25 años (inclusivos); la condición de participación es que no estudien titulaciones relacionadas con la publicidad, para que sus respuestas no estén condicionadas por sus conocimientos previos. Los adultos mayores (10 mujeres y 6 hombres) son personas autónomas (en relación con la capacidad de desplazamiento) con edades comprendidas entre los 65 y los 80 años que pertenecen a "centros para gente mayor" y realizan algún tipo de ocupación que los mantiene activos. Todos los sujetos acuden voluntariamente al laboratorio donde se realiza la parte experimental, tienen visión normal o corregida con gafas o lentes de contacto, y reciben un certificado de participación en la investigación.

De los sujetos iniciales, participan finalmente en el estudio 38, 25 jóvenes (18 mujeres y 7 hombres) y 13 adultos mayores ( 9 mujeres y 4 hombres). La mortandad experimental ha sido causada por la calidad de los registros obtenidos por el Eye Tracker, pues sólo se han considerado válidos los sujetos cuyos registros contienen un mínimo del $90 \%$ de los registros oculares.

\subsection{Diseño}

Estímulos. El estímulo objeto de estudio consiste en un fragmento (clip) del programa el Hormiguero cuyas características han sido descritas en el apartado Material. Con el objetivo de hacer más real el visionado, se utilizan 2 estímulos más, que tienen características parecidas al estímulo principal y que corresponden a diferentes programas y marcas anunciadas.

Variables: Las variables que forman parte del estudio son:

- La atención visual del sujeto mientras observa el estímulo (fragmento de TV). Sus resultados se obtienen del análisis del software del Eye Tracker a partir de las siguientes medidas:

- Número de fijaciones oculares (Fixation Count) -FC- en cada área de interés definida de la pantalla.

- Duración de las fijaciones oculares (Fixation Lenght) -FL- en cada área de interés definida de la pantalla.

- Tiempo (en segundos) que tarda la mirada del sujeto en hacer la primera fijación ocular (Time to first Fixation) -TFF- en cada área de interés definida de la pantalla.

- Reconocimiento cognitivo de la información, medido a partir del recuerdo espontáneo del contenido del clip. En su análisis se categorizan dos niveles que corresponden al reconocimiento, o no, de algún elemento publicitario (PUBLI) y de la marca (BRAND). 
- Grupo de edad: jóvenes y adultos mayores.

- Género: hombre o mujer.

Diseño. Se realiza un estudio exploratorio con un diseño con bloques (individuos) con asignación aleatoria de los estímulos.

\subsection{Procedimiento}

El procedimiento experimental se realiza en situación de laboratorio de forma individual con cada sujeto; todos los sujetos pasan por la misma situación experimental. Las fases seguidas son:

Fase 1. Bienvenida, explicación y firma de consentimiento de los participantes.

Fase 2. Calibración del Eye Tracker para asegurar que el registro de la mirada del sujeto es correcto (requisito para que el sujeto sea válido), es decir, que contiene un mínimo del 90\% de los registros oculares.

Fase 3. Presentación de los estímulos y recogida de datos a partir de los registros obtenidos del Eye Tracker. La instrucción que se da al sujeto es: "A continuación deberá mirar las imágenes como si estuviera mirando la TV normalmente”.

Fase 4. Registro oral del reconocimiento del contenido de las imágenes visualizadas. La instrucción que se da al sujeto es que "describa lo que ha visto y/o oído en las imágenes".

\section{Resultados}

El análisis de los resultados se realiza a partir de:

1. El análisis, la selección y la creación de los segmentos y de las áreas de interés (AOI) de la pantalla para su posterior análisis.

2. El análisis de la atención visual a la publicidad integrada y de la influencia del grupo de edad.

3. Análisis de la relación entre la atención visual de los sujetos a los elementos de la publicidad integrada y el reconocimiento posterior de los diferentes elementos de la publicidad, y de la influencia del grupo de edad.

El análisis estadístico se realiza con el programa PASW Statistics 17. Se utilizan estadísticos no paramétricos ya que la distribución normal de las variables no se cumple en el grupo de los sujetos adultos mayores. 


\subsection{Análisis, selección y creación de los segmentos y las áreas de interés (AOI) de la pantalla}

a) El primer análisis tiene como objetivo conocer la concentración de las fijaciones oculares (mirada) de los sujetos en las diferentes áreas de la pantalla durante el visionado del estímulo objeto de estudio (fragmento de programa de TV con publicidad integrada). Para ello se analiza, con el software del Eye Tracker, el mapa de calor (heatmap) correspondiente al visionado de todo el estímulo por parte de los sujetos. La figura 1 (heatmap) muestra como las zonas calientes de la pantalla (con más concentración de fijaciones oculares) son la central e inferior de la pantalla, que corresponden a las zonas donde aparecen el packaging (zona central) y el banner (zona inferior). En blanco y negro las zonas más calientes son las más oscuras; en color las zonas más calientes son, de más a menos, de color rojo, amarillo y verde.

Fig. 1 Heatmap del estímulo (fragmento de TV con publicidad integrada)

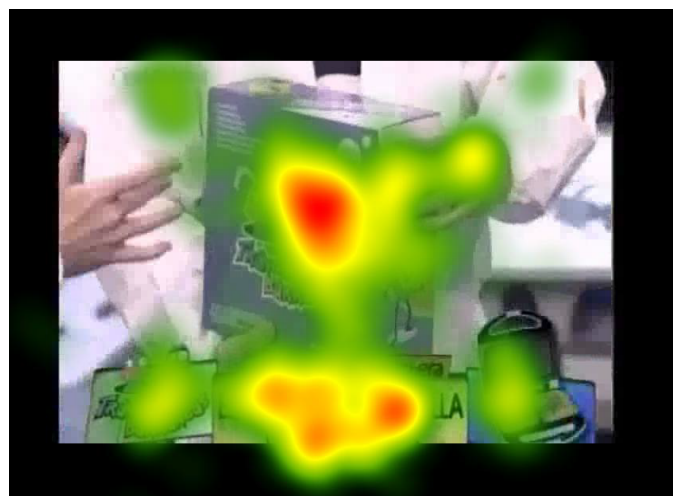

b) A continuación se seleccionan los 10 segundos del estímulo (clip) durante los cuales aparecen los elementos visuales de la publicidad integrada objeto de estudio (IA): packaging y banner animado y se determinan las áreas de la pantalla donde aparecen estos elementos.

c) A partir de la "AOI tool" del software TOBII (Eye Tracker) se interactúan las informaciones obtenidas en a) y b) (zonas calientes del segmento y zonas donde aparece la publicidad integrada -IA-), se crean los clusters que posteriormente serán las áreas de interés (AOI) sobre las cuales se realizará el análisis, y se obtienen y definen las 2 áreas de interés en las cuales se centrará el análisis cuantitativo de las fijaciones oculares (figura 2): el packaging (AOI de la zona superior central) que sostienen el locutor y los invitados y el banner (AOI de la zona inferior) en el que aparecen la marca (en la parte central) y los elementos publicitarios. El resto de la pantalla se define como área de no interés (NoAOI); su definición es importante puesto que es importante conocer las fijaciones oculares que los sujetos dispensan en la zona donde no aparece la IA mientras ésta ocupa una parte de la pantalla. 
Fig. 2 Áreas de interés objeto de estudio

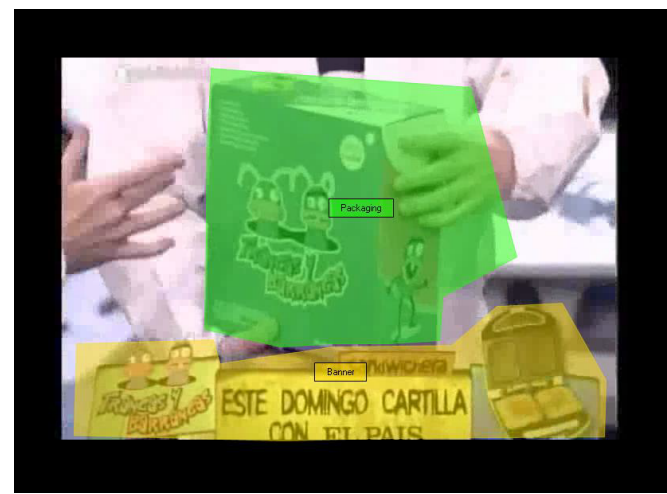

\subsection{Análisis de la atención visual a la publicidad integrada y de la influencia del grupo de edad}

El análisis de la atención visual se realiza a partir de las características de las fijaciones oculares obtenidas con el Eye Tracker (Número: Fixation Count -FC-, duración: Fixation Lenght -FL- y Time to First Fixation -TFF-), en cada área de interés de la pantalla (packaging, banner y NoOAI) y en cada grupo de edad. La Tabla 1 contiene las medias y las desviaciones estándar (SD) de las características de las fijaciones en cada grupo de edad y los valores estadísticos y el grado de significación obtenidos en las comparaciones entre los dos grupos de edad.

Tabla 1. Atención visual (características de las fijaciones oculares) en cada zona de la pantalla y en cada grupo de edad.

\begin{tabular}{|l|l|ll|l|lc|}
\hline $\begin{array}{c}\text { Atención } \\
\text { visual }\end{array}$ & \multicolumn{1}{|c|}{$\begin{array}{c}\text { Zona } \\
\text { pantalla }\end{array}$} & \multicolumn{2}{|c|}{$\begin{array}{c}\text { Jóvenes } \\
\text { Media (SD) }\end{array}$} & \multicolumn{2}{c|}{$\begin{array}{c}\text { Mayores } \\
\text { Media (SD) }\end{array}$} & \multicolumn{2}{c|}{$\begin{array}{c}\text { Mann Witney Test } \\
\text { Valor }\end{array}$} \\
Significación
\end{tabular}

** diferencias estadisticamente significativas

El gráfico 1 muestra los resultados del análisis de la concentración de las fijaciones oculares (Fixation Count -FC-) en cada zona de la pantalla y en cada 
grupo de edad. En él se observa como la distribución de las medias de las FC difiere en cada área de la pantalla; estas diferencias se mantienen en los dos grupos y son estadísticamente significativas $(\mathrm{p}<.000)$-Friedman Test-) en el sentido que las FC dispensadas a la NoAOI son inferiores a las dispensadas a los elementos de la publicidad integrada (al packaging y al banner), que no difieren estadísticamente entre sí, lo cual significa que durante la aparición de la Publicidad Integrada en la pantalla, sus elementos captan mayoritariamente las fijaciones oculares de los sujetos. Sólo se han encontrado diferencias estadísticamente significativas (MannWitney Test) entre los dos grupos en las FC dispensadas a la NoAOI, en el sentido que la gente mayor dispensa más FC a la NoAOI que los jóvenes $(p=.007)$.

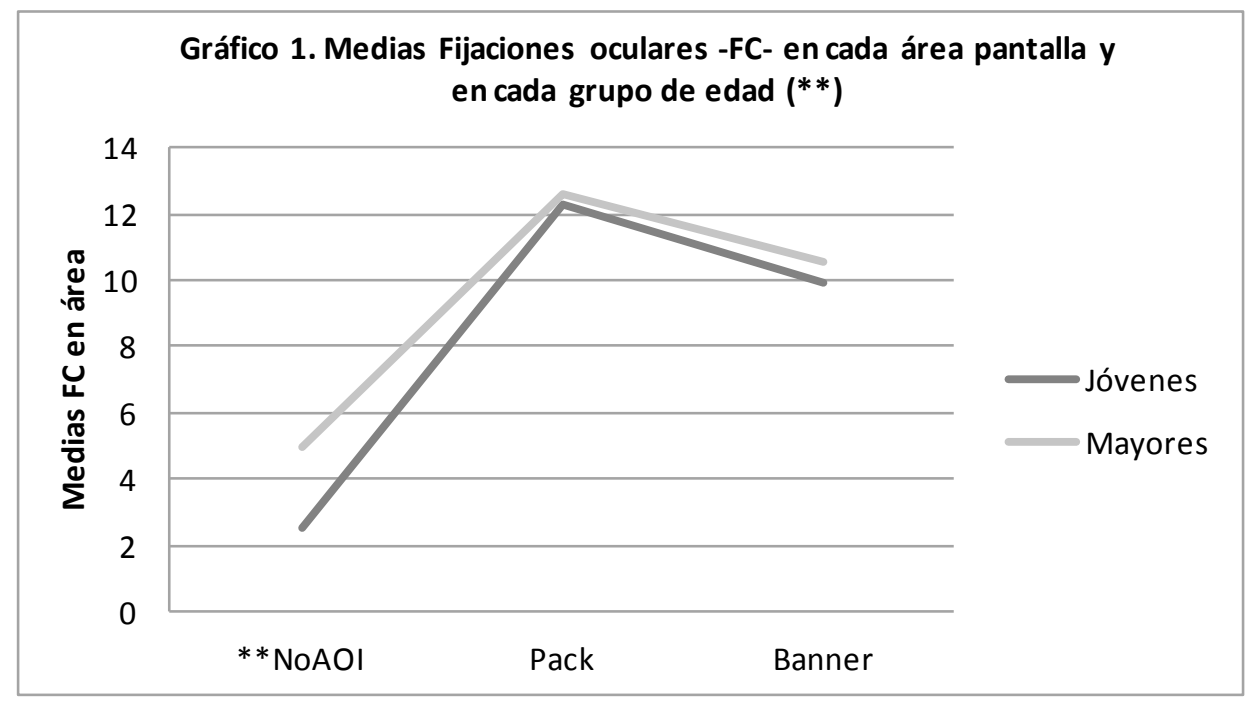

** Diferencias estadísticamente significativas

El gráfico 2 muestra los resultados del análisis de la duración de las fijaciones oculares (Fixation Lenght -FL-) en cada zona de la pantalla y en cada grupo de edad. Como se puede ver, las FL en las 3 zonas son similares en los jóvenes y en los adultos mayores y en la comparación entre los dos grupos no se han encontrado diferencias estadísticamente significativas (MannWitney Test). El gráfico 2 muestra también como la duración de las fijaciones (FL) difiere en cada área de la pantalla; estas diferencias se mantienen en los dos grupos y son estadísticamente significativas $(\mathrm{p}<.000)$-Friedman Test-) en el sentido que la duración de las fijaciones ocularers (FL) dispensadas al packaging es superior a la del banner y a la de la NoAOI, que no difieren entre sí, lo cual quiere decir que durante la aparición de la publicidad integrada las fijaciones dispensadas por los sujetos al packaging son más largas que las dispensadas al banner o a la NoAOI. 
El gráfico 3 muestra los resultados del análisis del tiempo que tarda la mirada de los sujetos en fijarse en cada área de la pantalla (Time to First Fixation -TFF-). Las diferencias de TFF en cada área entre los sujetos jóvenes y los mayores no son estadísticamente significativas (Mann Witney Test), si bien las miradas de los sujetos mayores tienden a ser más rápidas (inferiores) en la NoAOI, es decir, durante la emisión de la publicidad integrada, las miradas de los adultos mayores tienden a desviarse más rápidamente que las de los jóvenes hacia la zona de la pantalla que no contiene publicidad integrada (NoAOI). El gráfico 3 muestra también como el TFF difiere en cada área; estas diferencias, que se mantienen en los dos grupos de edad, son estadísticamente significativas ( $\mathrm{p}<.000$-Friedman Test-) en el sentido que el TFF es inferior (prácticamente nulo) en el packaging, seguido del TFF del banner y del de la NoAOI, lo cual quiere decir que durante la emisión de la publicidad integrada, la mirada de los sujetos, se fija rápidamente en sus elementos, especialmente en el packaging, que la capta de forma inmediata.

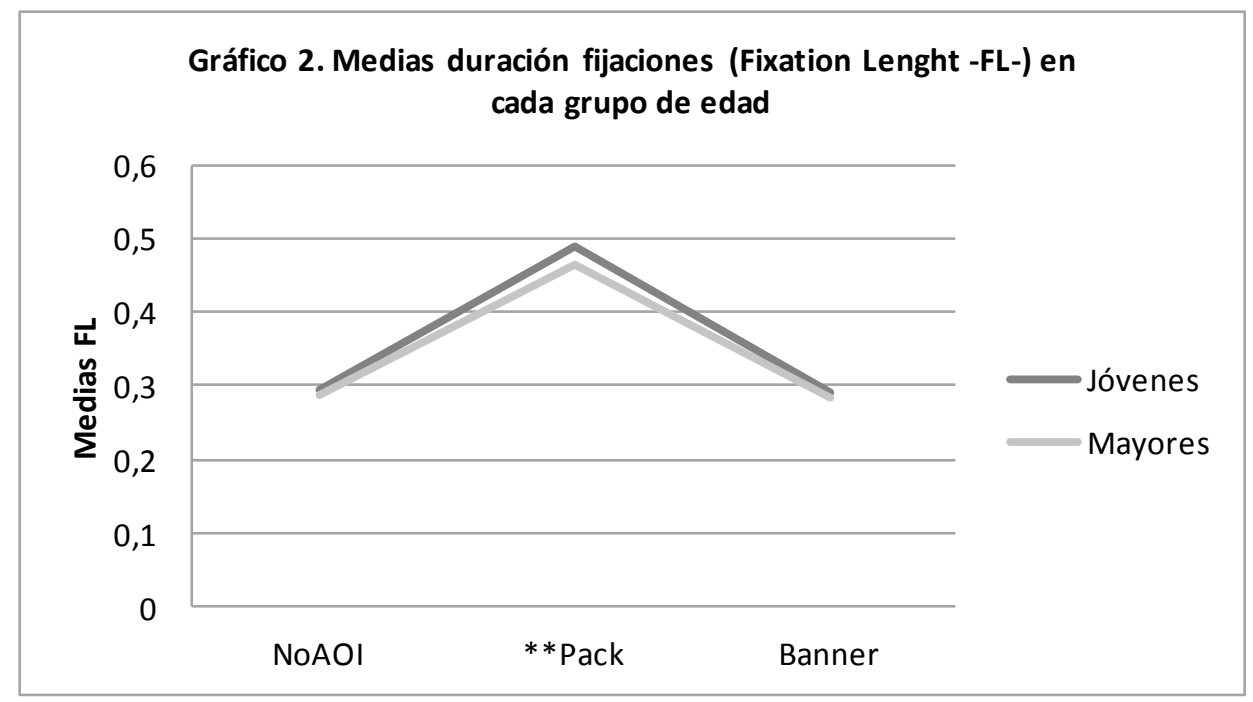

** Diferencias estadísticamente significativas $(p<.000)$ 


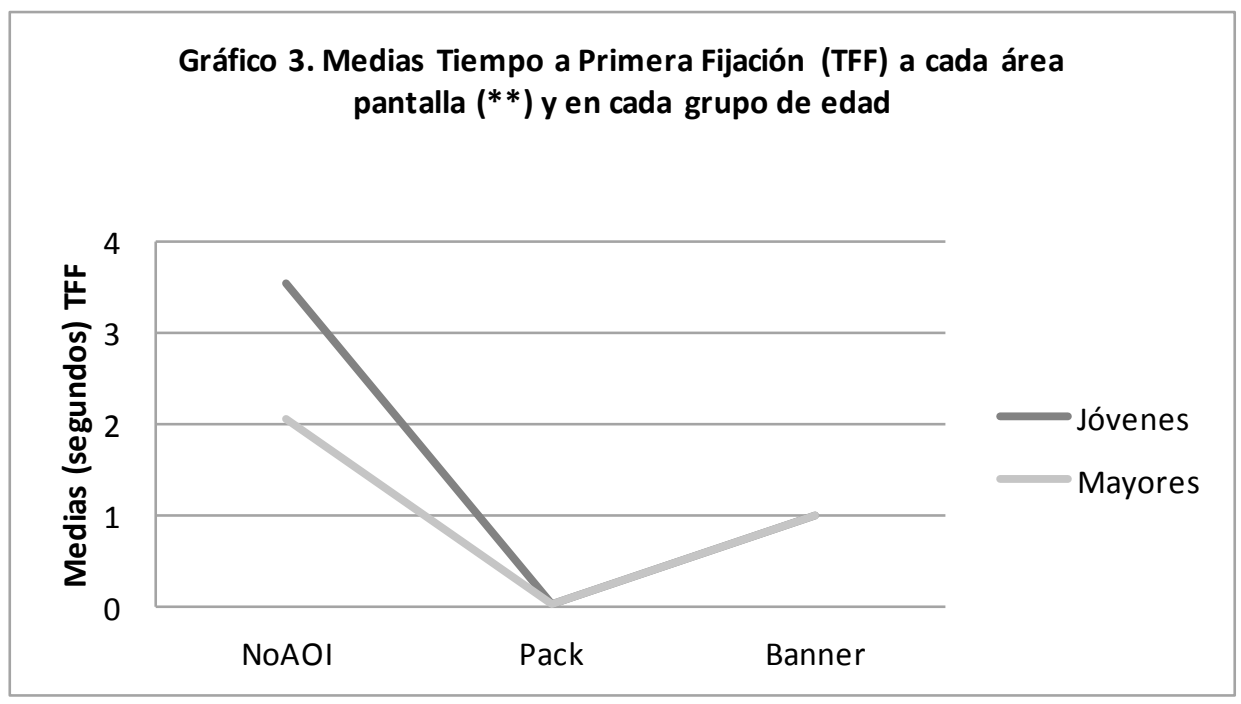

** Diferencias estadísticamente significativas $(p<.000)$

\subsection{Análisis del reconocimiento del contenido publicitario en cada grupo de edad.}

El análisis del reconocimiento del contenido publicitario se realiza a partir del recuerdo espontáneo de los elementos publicitarios del estímulo (clip) que corresponden al recuerdo de algún elemento publicitario (PUBLI) y al recuerdo de la marca (BRAND). Los resultados (Chi-Squart Test) muestran que no hay diferencias estadísticamente significativas en el reconocimiento de los elementos publicitarios ni de la marca entre los grupos de edad. El Gráfico 4 muestra como aproximadamente la mitad de los sujetos (jóvenes y mayores) reconoce algún elemento, publicitario (PUBLI) del fragmento de TV visionado. Sin embargo, se han encontrado diferencias estadísticamente significativas $(p=.001)$ en el reconocimiento de la marca (BRAND), en relación al no reconocimiento, en el sentido que la mayoría de sujetos (un 84\%) no la reconocen. 


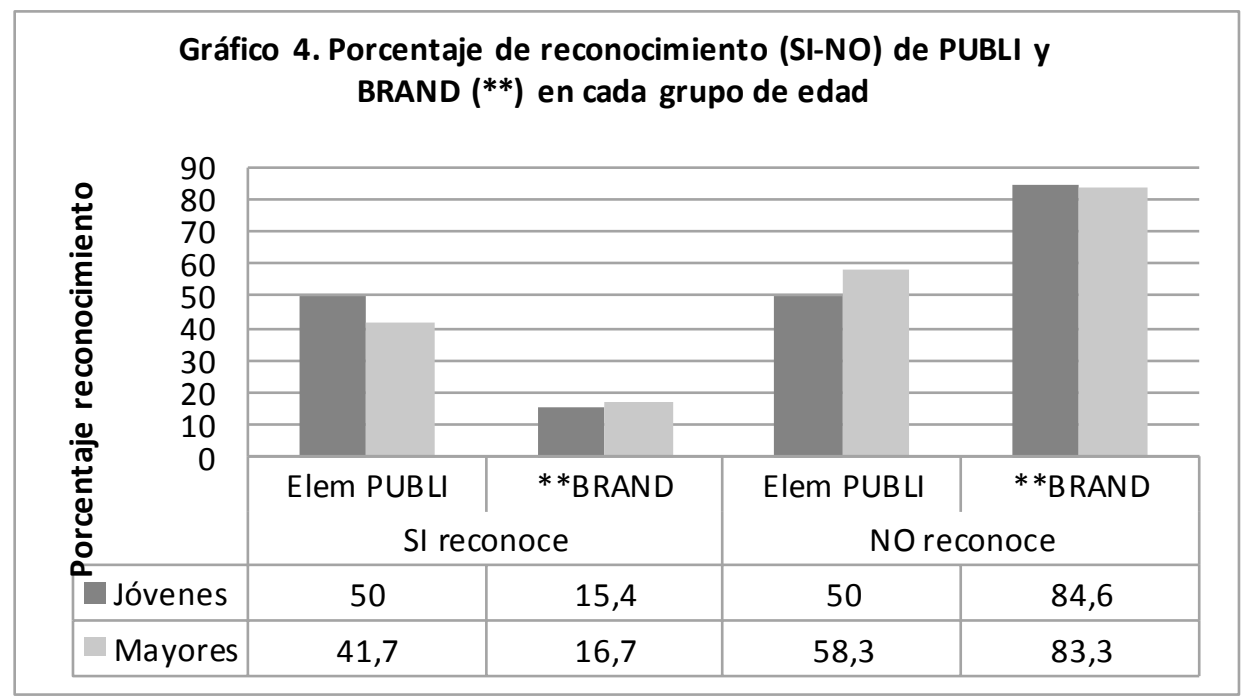

**Diferencias estadisticamente significativas $(p=.001)$

En el grupo de los jóvenes se han encontrado diferencias estadísticamente significativas (Mann Witney test) entre las mujeres y los hombres $(p=.01)$ en el sentido que un porcentaje superior de hombres $(18,5 \%)$ reconoce la marca mientras sólo lo hace el $9,1 \%$ de las mujeres jóvenes.

\subsection{Relación entre la atención visual y el reconocimiento del contenido publicitario}

Con el objetivo de conocer si existe una relación entre la atención visual (características de las fijaciones oculares) dispensada a los elementos de la publicidad integrada (packaging y banner) y el reconocimiento posterior de los elementos publicitarios (PUBLI) o de la marca (BRAND), se comparan las características de las fijaciones oculares dispensadas a los elementos de la publicidad integrada ( $p a-$ ckaging y banner) entre los sujetos que han reconocido algún elemento de la publicidad o la marca y los que no. Puesto que en los apartados anteriores no se han encontrado diferencias entre los dos grupos de edad ni en las características de la atención visual ni en el reconocimiento de la publicidad, los siguientes análisis de realizan de forma global, con todos los sujetos. La Tabla 2 contiene los resultados obtenidos (medias, SD, valores estadísticos y nivel de significación) en el análisis de las fijaciones oculares dispensadas a los elementos de IA (packaging y banner) por los sujetos que reconocen algún elemento de la publicidad (PUBLI) y los que no. La Tabla 3 contiene los resultados obtenidos (medias, SD, valores estadísticos y nivel de significación) en el análisis de las fijaciones oculares dispensadas a los elementos de la publicidad integrada -IA- (packaging y banner) por los sujetos que reconocen algún elemento de la marca (BRAND) y los que no. 
Tabla 2. Atención visual (características de las fijaciones oculares) en las áreas de publicidad integrada (packaging y banner) en los sujetos que reconocen elementos de la publicidad (PUBLI) y en los que no los reconocen.

\begin{tabular}{|c|c|c|c|cc|}
\hline $\begin{array}{c}\text { Atención } \\
\text { visual }\end{array}$ & $\begin{array}{c}\text { Publicidad } \\
\text { Integrada } \\
\text { (IA) }\end{array}$ & $\begin{array}{c}\text { SI reconoce } \\
\text { PUBLI } \\
\text { Media (SD) }\end{array}$ & $\begin{array}{c}\text { NO reconoce } \\
\text { PUBLI } \\
\text { Media (SD) }\end{array}$ & $\begin{array}{c}\text { Mann Witney Test } \\
\text { Valor }\end{array}$ \\
\hline $\begin{array}{c}\text { Fixation } \\
\text { Count }\end{array}$ & $\begin{array}{c}\text { Packaging } \\
\text { Banner }\end{array}$ & $12,61(3,97)$ & $12,15(3,78)$ & 168,5 & $\mathrm{~ns}$ \\
-FC- & $10,60(5,64)$ & $9,70(4,80)$ & 163,5 & $\mathrm{~ns}$ \\
\hline Fixation & Packaging & $0,45(.177)$ & $0,50(.277)$ & 167 & $\mathrm{~ns}$ \\
Lenght & Banner & $0,29(.064)$ & $0,28(.0,85)$ & 154 & $\mathrm{~ns}$ \\
-FL- & & & & & \\
\hline TFF & Packaging & $0,03(.137)$ & $0,01(.040)$ & 178 & $\mathrm{~ns}$ \\
& Banner & $0,98(.709)$ & $1,01(.567)$ & 149 & $\mathrm{~ns}$ \\
\hline
\end{tabular}

Tabla 3. Atención visual (características de las fijaciones oculares) en las áreas de publicidad integrada (packaging y banner) en los sujetos que reconocen la marca (BRAND) y en los que no la reconocen.

\begin{tabular}{|c|c|c|c|cc|}
\hline $\begin{array}{c}\text { Atención } \\
\text { visual }\end{array}$ & $\begin{array}{c}\text { Publicidad } \\
\text { Integrada } \\
\text { (IA) }\end{array}$ & $\begin{array}{c}\text { SI reconoce } \\
\text { BRAND } \\
\text { Media (SD) }\end{array}$ & $\begin{array}{c}\text { NO reconoce } \\
\text { BRAND } \\
\text { Media (SD) }\end{array}$ & $\begin{array}{c}\text { Mann Witney Test } \\
\text { Valor }\end{array}$ & Significación \\
\hline $\begin{array}{c}\text { Fixation } \\
\text { Count }\end{array}$ & $\begin{array}{c}\text { Packaging } \\
\text { Banner }\end{array}$ & $13,00(4,56)$ & $12(3,75)$ & 83,5 & $\mathrm{~ns}$ \\
-FC- & $14,00(5,17)$ & $9,40(4,91)$ & 48,5 & $* * .05$ \\
\hline Fixation & Packaging & $0,33(.137)$ & $0,50(.239)$ & 46 & $* * .04$ \\
Lenght & Banner & $0,28(.089)$ & $0,28(.074)$ & 78 & $\mathrm{~ns}$ \\
-FL- & & & & & $\mathrm{ns}$ \\
\hline TFF & Packaging & $0,114(.232)$ & $.008(.032)$ & 70 & $\mathrm{~ns}$ \\
\hline
\end{tabular}

** diferencias estadísticamente significativas

Los resultados (Gráfico 5) no muestran diferencias estadísticamente significativas (Mann Witney Test) en las fijaciones oculares (FC) dispensadas en las zonas de IA (packaging y banner) entre los sujetos que reconocen algún elemento publicitario (PUBLI) y los que no, si bien tienden a ser algo superiores en los sujetos que los recuerdan. En cuanto al reconocimiento de la marca (BRAND), no se han encontrado diferencias estadísticamente significativas en las FC del packaging entre los sujetos que recuerdan la marca (BRAND) y los que no, y sí se han encontrado diferencias estadísticamente significativas $(\mathrm{p}=.05)$ en las $\mathrm{FC}$ dispensadas al banner, en el sentido que son superiores en los sujetos que reconocen la marca que en los que no la reconocen. Estos resultados se mantienen en los dos grupos de edad. 


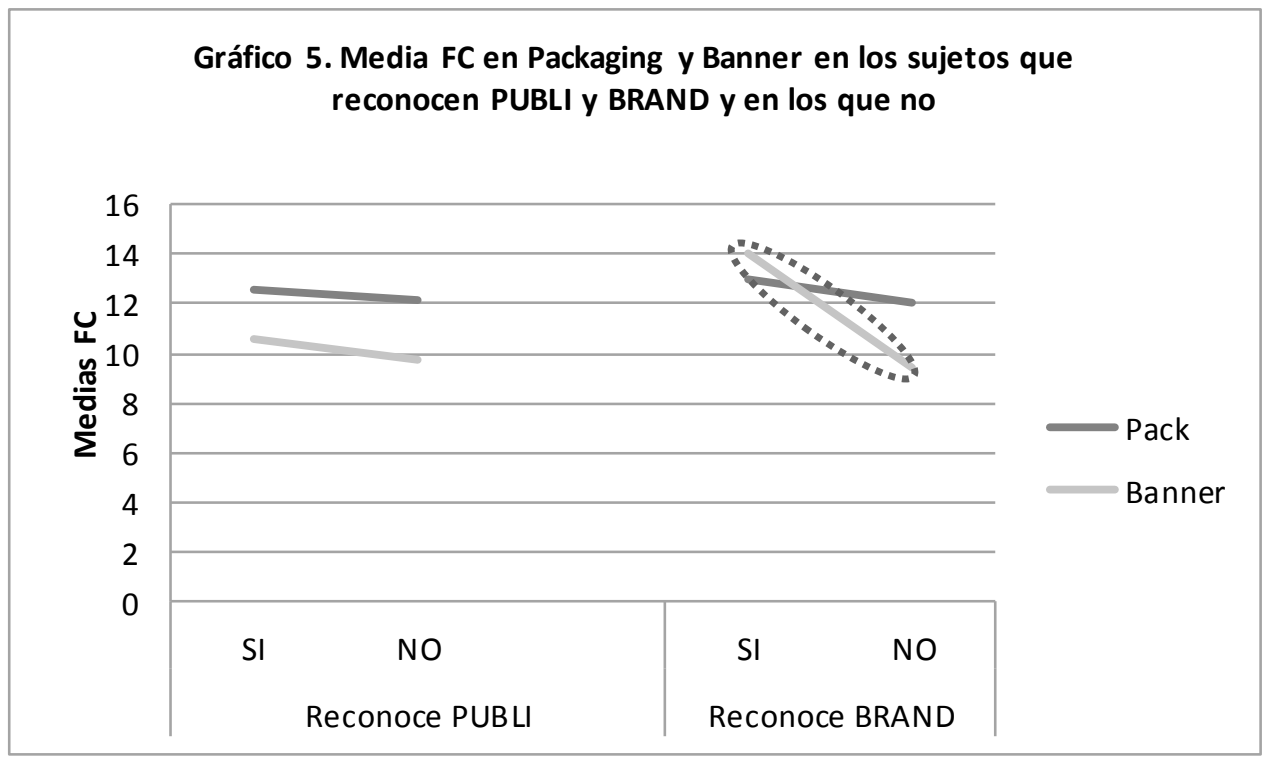

En el análisis de la duración de las fijaciones (Fixation Lenght -FL-), los resultados (Gráfico 6) no muestran diferencias estadísticamente significativas (Mann Witney Test) en la duración de las fijaciones (FL) en el packaging y el banner entre los sujetos que reconocen algún elemento publicitario (PUBLI) y los que no. En cuanto al reconocimiento de la marca (BRAND), no se han encontrado diferencias estadísticamente significativas en las FL en el banner entre los sujetos que la reconocen y los que no, y sí se han encontrado diferencias estadísticamente significativas $(\mathrm{p}=.04)$ en las FL dispensadas al packaging, en el sentido que son superiores en los sujetos que no reconocen la marca en relación a los que la reconocen. Estos resultados se mantienen en los dos grupos de edad (jóvenes y mayores), lo cual quiere decir que el hecho de fijarse durante más tiempo en el packaging, dificulta el reconocimiento de la marca que aparece simultáneamente en el banner. 


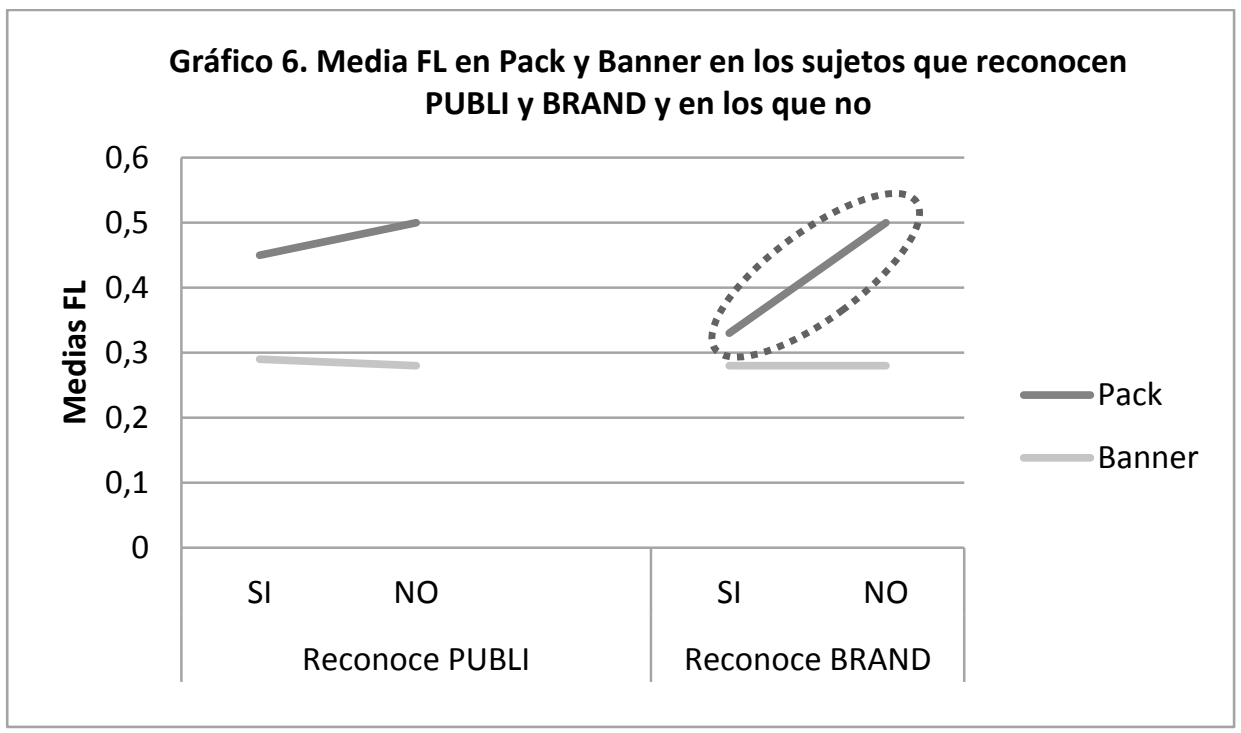

En el análisis de la relación entre el reconocimiento de la publicidad y la marca y el tiempo que tarda la mirada hasta la primera fijación en cada área (TFF), los resultados (Gráfico 7) no muestran diferencias estadísticamente significativas en el TFF de las áreas de IA (packaging y banner) entre los sujetos que reconocen algún elemento publicitario (PUBLI) o la marca (BRAND) y los que no; ahora bien, los sujetos que reconocen la marca tienden a tener fijaciones más rápidas (inferiores) al banner (donde aparece) que los que no la reconocen y más lentas al packaging. Estos resultados se mantienen en los dos grupos de edad.

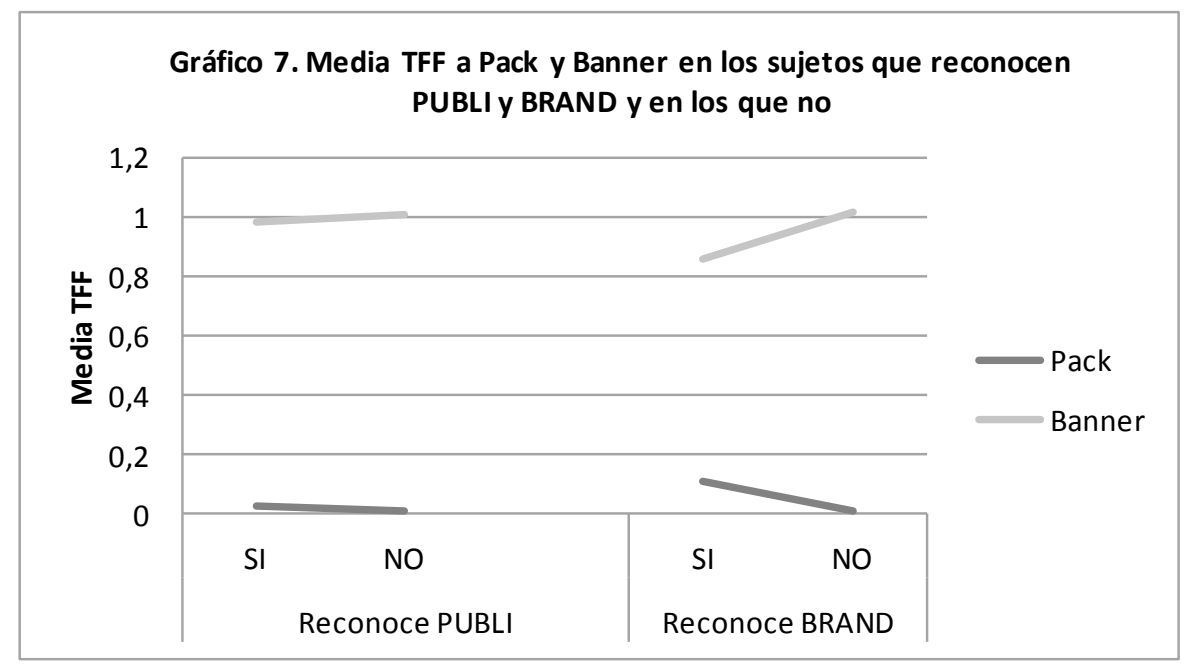




\section{Conclusiones}

Al inicio del trabajo se plantea la pregunta: ¿hasta qué punto la publicidad integrada en el contenido televisivo pasa inadvertida en el telespectador? y, de no ser así, ¿cuál es el mecanismo atencional que opera en este proceso? A nivel general, podemos concluir que el sujeto atiende (a nivel pre-consciente) la publicidad integrada (IA) y que durante su aparición las miradas se fijan rápidamente en sus elementos (el packaging y el banner) y dejan de fijarse en el resto de la pantalla. Los resultados obtenidos también permiten concluir que durante la emisión de IA, las fijaciones oculares se concentran en las zonas de la pantalla que contienen sus elementos (packaging y banner). Se cumple así la primera hipótesis según la cual podemos aceptar que los elementos de IA, si bien aparecen como elementos distractores, captan la atención del telespectador, dando soporte a la teoría de la captura atencional (RUZ y LUPIÁÑEZ, 2002) y a la del procesamiento de los flancos o distractores (PIETERS y WEDEL, 2007).

En general, las características de la atención visual a la publicidad integrada (IA), dependen más del formato publicitario que de la edad de los sujetos, puesto que, en la muestra estudiada, la atención visual de los sujetos jóvenes y la de los adultos mayores no difiere entre sí, lo cual nos permite confirmar sólo parcialmente la segunda hipótesis. Así, la duración de las fijaciones oculares difiere en los dos elementos de IA estudiados en el sentido que son más largas en el packaging que en el banner; este hecho puede ser debido a que el packaging (en el ejemplo estudiado) capta de forma más continua la atención del telespectador debido a su posición en la parte central de la pantalla y a que su aparición está reforzada verbalmente por la locución de los personajes del programa.

La publicidad integrada (IA) objeto de este estudio es, pues, atendida. Pero, ¿hasta qué punto es procesada? En el caso estudiado, podemos concluir que el reconocimiento de los elementos de la publicidad es bastante alto (lo hacen aproximadamente la mitad de los sujetos) pero el reconocimiento de la marca es bajo, puesto que sólo la ha reconocido un $15 \%$ de los sujetos. Estos resultados se dan por igual en los dos grupos (jóvenes y adultos mayores), lo cual puede ser debido al tipo de medida utilizada en el reconocimiento, ya que se trata de un recuerdo inmediato de la información en una tarea en la que los sujetos (especialmente los mayores) estaban muy motivados; ésto ha producido, junto con un mayor conocimiento del anunciante, que los sujetos mayores identificaran algo mejor la marca que los jóvenes. La hipótesis tercera se cumple, pues, parcialmente.

¿Hasta qué punto la atención visual dispensada a los elementos de la publicidad integrada influye en su reconocimiento? De los resultados obtenidos podemos concluir que la relación entre la atención visual a la IA y su posterior reconocimiento se dan de forma similar en los sujetos jóvenes y en los adultos mayores y, lo que es aún más importante, el hecho de reconocer algún elemento de la publicidad no depende directamente de la atención dispensada a los elementos de la IA, si bien la tendencia es que los sujetos con un nivel de reconocimiento superior dispensan una mayor atención. Sin 
embargo, el reconocimiento de la marca sí que depende del nivel de atención del sujeto al elemento donde aparece, el banner, puesto que los sujetos que reconocen (pocos) la marca, tienen más fijaciones oculares en el banner que los que no la reconocen y además, el tiempo que su mirada tarda en fijarse en el banner es inferior. La hipótesis cuatro, por tanto, se cumple únicamente en relación al reconocimiento de la marca.

Estos resultados nos permiten concluir, siguiendo el planteamiento de HEATH (2009) que el proceso atencional a la publicidad integrada se produce en diferentes niveles, de los cuales se constata el primer nivel, el pre-consciente, pre-atentivo e involuntario, en el que las fijaciones oculares del sujeto exploran los elementos publicitarios de forma inconsciente $\mathrm{y}$, en función de otros mecanismos de selección, se procesarán en un nivel superior hasta el punto de ser reconocidos por el telespectador. No tenemos evidencias de cómo se procesan los niveles intermedios, si bien los datos apuntan al hecho que en el último nivel (elaboración y reconocimiento de la atención) intervienen otros elementos que van más allá del procesamiento pre-atencional y que, según BIEL (2009), están más relacionados con los patrones emocionales. Hay que considerar, no obstante, la existencia de otros planteamientos en relación al procesamiento inconsciente de la información, entre los que destacan los de HASSIN, ULEMAN, y BARGH (2007), para quienes The New Unconscience, si bien es básicamente cognitivo, está también relacionado con las emociones, las motivaciones e incluso con niveles de control y de metacognición; el estudio del procesamiento de la publicidad desde esta perspectiva, abre nuevas vías de investigación, que podrían relacionar el proceso inconsciente de la publicidad, con las futuras intenciones de compra.

Tal y como se ha planteado en el estudio predecesor a este trabajo (AÑAÑOS, 2011), consideramos la televisión, y en especial la inclusión simbiótica de publicidad integrada, como una herramienta de comunicación eficaz para las marcas, al menos, desde el punto de vista cognitivo, puesto que para medir de forma directa su eficacia, este tipo de estudios se deberían completar con el empleo de escalas de actitudes o de intención de compra o de elección del producto. Es desde esta perspectiva más global, desde la cual podemos concluir que la publicidad integrada o por extensión, el Content Integrated Marketing, puede satisfacer de forma amplia y efectiva las necesidades de comunicación de la marca -desde las campañas de brand awareness, pasando por campañas de respuesta directa (direct marketing)-, hasta ser capaz de crear una emoción que mueva al público consumidor de contenidos a la acción social (evangelism marketing), una interacción que irá más allá del consumo del producto, equiparada al activismo pro-marca y al WOM (word of mouth).

Viendo sus potencialidades, es necesario plantearse los elementos que harán crítica esta efectividad y que, por tanto, pueden ser objeto de posteriores estudios para desgranar, estudiar y proponer una metodología que sistematice y racionalice el estudio de la efectividad de este tipo de campañas a nivel concreto, acotando así la casuística existente en algunos estudios publicitarios. Recomendamos que en futuras investigaciones se considere como variable independiente el tiempo que ocupa la IA en el estímulo presentado (clip de programa), así como también el estudio del nivel de conocimiento 
previo de la marca y del programa por parte de los targets estudiados, que permita analizar y conocer hasta qué punto la experiencia previa afecta al procesamiento de la publicidad integrada.

En conclusión, esta aportación al estudio del procesamiento de la publicidad desde la perspectiva de la psicología, en especial desde el estudio de los procesos cognitivos, aborda cuestiones novedosas sobre la publicidad integrada, dando respuesta a algunas preguntas y planteando otras nuevas, abriendo así la puerta a posteriores investigaciones que sigan indagando sobre esta materia desde esta perspectiva interdisciplinar.

\section{Referencias bibliográficas}

Aввот, A. (2006): «Neuroprosthetics: In search of the sixth sense». Nature, 442, 125-27.

ALTMANN, G.T.M. y KAMIDE, Y. (2009): Discourse-mediation of the mapping between language and the visual world: Eye moviments and mental representation. Cognition, núm. 111, p. 55-71.

AÑAÑOS, E. (2011): Processament i eficàcia de les noves formes (formats no convencionals) de publicitat televisiva. Estudio de investigación del Consell de l'Audiovisual de Catalunya. DOGC: $103 / 2009$. Web visitada el 1/06/2011.

AÑaÑos, E. y Valli, A. (2011): «Programa, Publicidad, Marca o Producto? Procesamiento consciente e inconsciente de la Publicidad No Convencional (PNC) televisiva». Actas del $I V$ Congreso Internacional sobre Análisis Fílmico. Nuevas tendencias e hibridaciones de los discursos audiovisuales en la cultura digital contemporánea, Castellón, Universitat Jaume I, Cd-ROM, 403-419.

AÑaÑos, E., Estaún, S., Tena, D., MAs, M.T. y Valli, A. (2009): Psicología y Comunicación Publicitaria. Barcelona: Publicacions de la UAB.

BIEL, A. (2005): «Recognition, recall and persuasión. The advertising ming:ground-breaking insights into how our brains respond to advertising». Advertising Educational Foundation. http://www.aef.com/pdf/advertised_mind_16.pdf. Web visitada el 1/06/2011.

BIEL, A. (2009): «Economic recession advertising, what is?». Business school, (1).

BOTTA, F. y LUPIÁÑEZ, J. (2010): «The distribution of exogenous and endogenous attention in visuo-spatial working memory». Actas de la 1 st joint Conference of the EPS (Experimental Psychology Society) and SEPEX (Sociedad Española de Psicología Experimental).

BRASEL, A.S., y GIPS, J. (2008): «Breaking Throught Fast-Forwarding: Brand information and Visual Attention». Journal of Marcketing, núm. 72 (6).

Charchat-Fichman, H., Caramelli, P., SAmeshima, K. \& Nitrini, R. (2005): «Decline of cognitive capacity during aging». Revista Bras Psiquiatria. 27 (12), pp. 79-82.

DURANTE, P. y PEDRO P. (2004): Terapia ocupacional en geriatría: principios y práctica. $2^{\mathrm{a}}$ Edición. Editorial Masson. Barcelona

IAB (Interactive Advertising Bureau) - Estándares de Formatos Publicitarios Interactivos. http://www.iabspain.net/ver.php?mod=contenido\&identificador=19 Web visitada el $13 / 03 / 2011$.

DRU, J-M. (1997). Disruption: overturning conventions and shaking up the marketplace. New Jersey: John Wiley \& Sons editions. 
GRIMES, A. (2006): «Towards an integrated model of low attention advertising effects. A perceptual-conceptual framework». European Journal of Marketing, vol 42, núm, 1-2-69-86.

HEATH, R. (2009): «Emotional Engagement: How television Builds Brands at Low Attention». Journal of Advertising Research, March, p. 62-73.

HeAth, R. NAiRN, A.C. y BotTomley, P.A. (2009): «How effective is creativity? Emotive content in TV advertising does not increase attention». Journal of advertising research, 47 (December), 450-463.

HENDERSON, J.M. (1992): Visual attention and eye movement control during reading and picture viewing. in K. Rayner (Ed.). Eye movements and visual cognition: Scene perception and reading. New York: Springer-Verlag, 260-283.

HASSIN, R.R., UlLEMAN, J.S. Y BARGH, J.A. (2007): The New Unconscious. New Jersey: Oxford University Press.

LACHTER, J., FORSTER, K. y RUTHRUFF, E. (2004): «Forty-Five Years After Broadbent (1958): Still No Identification Without Attention». American Psychological Association, núm. 111, vol. 4, p. 880-913.

PACHeCo-UngetTI, A., LuPiÁÑEZ, J. y ACOSTA, A. (2009): «Atención y ansiedad: relaciones de alerta y control cognitivo con ansiedad de rasgo». Psicológica, núm.30, p. 1-25.

Pedraja, M.J., Montoro, P.R. y García-SeVilla, J. «Cómo la distancia entre estímulos modula el efecto de compatibilidad de los flancos, bajo diferentes condiciones de relación objetivo-distractores». En: AÑAÑOS, E., ESTAUN, S. y MAS, M.T. (2010), La atención (VI). Un enfoque interdisciplinar. Barcelona (España): Montflorit Edicions, p. 57-68.

PIETERS, R. y WedEL, M. (2007): «Goal Control of Visual Attention to Advertising: The Yarbus Implication». Journal of Consumer Research, núm. 34, p. 224-233.

Posner, M.I. y PERTERSEN, S.E. (1990): «The attention system of the human brain». Annual review of Neuroscience, núm. 13, p. 25-42.

RuZ, M. y LuPIÁÑEZ, J. (2002): «A review of Attentional capture. On its Automaticity and Sensitivity to Endogenous Control». Psicológica, núm. 23, vol. 2, p. 283-309.

SANCHEZ GIL y PEREZ MARTíNEZ (2008). «The cognitive functioning in the elderly: attention and perception in the older adult». Biblioteca Virtual en Salud de Cuba.

http://bvs.sld.cu/revistas/mgi/vol24_2_08/mgil1208.htm. Web visitada el 1/06/2011.

VAN REIJMERSDAL, E. (2009): «Brand Placement prominence: good for memory, bad for attitudes?», Journal of advertising research, 49 (2), 151-153.

WEDEL, M. y PIETERS, R. (2007): «Informativeness of eye movements for visual marketing: Six cornerstones». Visual Marketing: From Attention to Action. New York: Lawrence Erlbaum. 